\title{
HUBUNGAN DUKUNGAN KELUARGA DENGAN TINGKAT DEPRESI PADA LANSIA DI WILAYAH KERJA PUSKESMAS MARUNGGI TAHUN 2017
}

\author{
Dini Qurrata Ayuni \\ STIKes Piala Sakti Pariaman \\ Email: ayunidini80@gmail.com
}

\begin{abstract}
Elderly is a natural process that accompanied the decline of their physical, psychological and social are intertwined with one another. In conditions such as the elderly, it can cause various health problems and mental disorders such as depression. In the face of the reality of living in order to obtain well-being in old age is determined by the participation and full support of the family. Methods: The purpose of this study was to determine the relationship between family support with depression in the elderly. This research uses descriptive correlational design with cross sectional method. The sample in this study were taken by purposive sampling of 114 elderly people. Research tools used questionnaires and questionnaires Family Support Geriatric Depression Scale (GDS), using a statistical test Chi Square test. Results: The results of this study showed no relationship between family support with depression in the elderly with a value of $p=$ 0.027 (pvalue <0.05). Discussion: Future studies are recommended for further study of the factors that can affect depression in the elderly and can see exactly which family support with the level of depression in elderly.
\end{abstract}

Keywords: Family support, depression,elderly

\begin{abstract}
ABSTRAK
Usia lanjut tahap akhir dari siklus hidup manusia, merupakan proses alamiah kehidupan yang tidak dapat dihindarkan dan akan dialami oleh setiap individu. Pada tahap ini individu mengalami banyak perubahan, baik secara fisik,mental, khususnya kemunduran dalam berbagai fungsi dan kemampuan yang pernah dimilikinya. Lansia merupakan proses alami yang disertai adanya penurunan kondisi fisik, psikologis,sosial yang saling berkaitan satu sama lain. Pada kondisi lansia seperti ini, dapat menimbulkan berbagai gangguan kesehatan dan gangguan mental sepertidepresi. Dalam menghadapi kenyataan hidup agar memperoleh kesejahteraan pada usia lanjut sangat ditentukan oleh peran serta dan dukungan penuh dari keluarga. Tujuan penelitian ini adalah untuk mengetahui hubungan antara dukungan keluarga dengan depresi pada lansia Penelitian ini menggunakan desain penelitian deskriptif korelasional dengan metode pendekatan cross sectional. Sampel dalam penelitian ini diambil secara purposive sampling sebanyak 114 lansia. Alat penelitian menggunakan kuesioner Dukungan Keluarga dan kuesioner Geriatric Depression Scale(GDS), uji statisti cmenggunakan uji Chi Square. Hasil penelitian ini menunjukan ada hubungan antara dukungan keluarga dengan depresi pada lansia nilai $\mathrm{p}=0,027$ (pvalue $<0.05$ ). Penelitian selanjutnya direkomendasikan untuk diteliti lebih lanjut tentang faktor yang dapat mempengaruhi depresi pada lansia dan lebih bisa melihat secara tepat dukungan keluarga dengan tingkat depresi pada lansia.
\end{abstract}

Kata kunci: Dukungan keluarga, depresi, lansia. 


\section{PENDAHULUAN}

Usia lanjut adalah tahap akhir dari siklus hidup manusia, merupakan bagian dari proses alamiah kehidupan yang tidak dapat dihindarkan dan akan dialami oleh setiap individu. Pada tahap ini individu mengalami banyak perubahan, baik secara fisik maupun mental, khususnya kemunduran dalam berbagai fungsi dan kemampuan yang pernah dimilikinya. Perubahan penampilan fisik sebagai bagian dari proses penuaan yang normal, seperti berkurangnya ketajaman panca indera, menurunnya daya tahan tubuh. Mereka juga kehilangan peran diri karena sudah pensiun atau tidak mampu mencari penghasilan, kedudukan sosial serta perpisahan dengan orang-orang yang dicintai. Kondisi diatas menyebabkan orang usia lanjut menjadi lebih rentan untuk mengalami problem mental, salah satunya adalah depresi. ${ }^{1}$

Peningkatan usia harapan hidup berdampak terhadap peningkatan jumlah lansia yaitu usia 60 tahun ke atas. Proporsi penduduk lansia di Indonesia mengalami peningkatan cukup signifikan, yakni mencapai 19,3 juta jiwa atau $7,18 \%$ dari total keseluruhan penduduk Indonesia tahun 2009, dan meningkat pada tahun 2012 dengan persentase populasi lansia adalah $7,58 \%$.

Secara psikologis, sesuai tahap perkembangan Erikson masa lanjut usia berada pada fase integritas versus keputusasaan, dimana individu melakukan tinjauan hidup (life review) yang merefleksikan kembali pada pengalaman, evaluasi, menafsirkan, dan selalu menafsirkan akan perubahan hidup antara lain pensiun, penyakit atau ketidakmampuan fisik, kematian pasangan, dan kebutuhan merawat pasangan. ${ }^{2}$ Tingginya stressor dan peristiwakehidupan yang tidak menyenangkan menimbulkan berbagai masalah mental dan psikososial seperti short term memory, kecemasan, kesepian, sampai pada depresi. ${ }^{3}$

Depresi pada lansia di dunia diperkirakan ada 500 juta jiwa dengan usia rata-rata 60 tahun. World Health Organization pada tahun 2012 menyebutkan bahwa setiap tahun terdapat 100 juta kasus depresi, dan diperkirakan tahun 2020 pola penyakit negara berkembang akan berubah menjadi depresi bipolar (Evy, 2012). Prevalensi depresi pada lansia di negara maju seperti Perancis juga menunjukkan angka yang cukup tinggi. Populasi usia $<64$ tahun sebanyak $34,4 \%$, populasi usia 65-74 tahun sebanyak 23,3\%, dan populasi usia lebih dari 75 tahun sebanyak $22,9 \%$ depresi. $^{3}$

Depresi pada lansia di Indonesia sebesar 11,6\%. Hasil laporan Riset Kesehatan Dasar 2013, prevalensi lansia usia 55-64 tahun yang mengalami depresi sebesar $15,9 \%$, pada lansia usia 65-74 tahun sebesar 23,2\%, dan pada lansia usia diatas 75 tahun sebesar $33,7 \%{ }^{4}$ Diperkirakan jumlah lansia pada tahun 2020 menjadi 28 juta jiwa atau 11,3\% (BPS, 2013). Sedangkan jumlah lansia Sumatera Barat pada tahun 2013 sebanyak 37,3795 jiwa 2. 5 Pada tahun 2010, jumlah lansia sebesar 23,9 juta $(9,77 \%)$ dengan usia harapan hidup 67,4 tahun. Peningkatan jumlah penduduk lansia ini antara lain disebabkan karena 
tingkat sosial ekonomi masyarakat yang meningkat, kemajuan di bidang pelayanan kesehatan, dan tingkat pengetahuan masyarakat yang meningkat. ${ }^{6}$

$$
\text { Depresi berakibat pada }
$$
berbagai masalah kesehatan pada lansia, adapun dampaknya seperti demensia (kemerosotan daya ingat), insomnia, penyakit jantung, darah tinggi dan stroke. ${ }^{7}$ American Heart Association

menyebutkanpada $\quad 6.700 \quad$ orang dewasa lansia dari berbagai etnik kulit putih, Afrika, China, dan Asia, menemukan bahwa depresi kronis secara signifikan dapat meningkatkan risiko stroke dan transient ischemic attack (TIA) hingga $59 \%$ pada orang dewasa paruh baya dan lanjut usia. Bahkan depresi ringanpun berkontributor dua kali lipat pada kejadian stroke ringan (Roetker \& Lutsey, 2014).Sehingga psikologis lansia seperti depresi harus diperhatikan . ${ }^{1}$

Lansia dengan gangguan alam perasaan depresi akan mengalami kesedihan yang berlebihan, murung, tidak bersemangat, perasaan tidak berharga, merasa kosong, putus harapan, selalu merasa dirinya gagal, tidak berminat pada ADL sampai ada ide bunuh diri (Yosep, 2009).Hal tersebut didukung oleh ahli fisiologi Hans Selye (1936 dalam Hidayat, 2009), yang menganalisis reaksireaksi hormonal berantai sebagai akibat adanya tekanan emosional yang berlebihan menunjukkan bahwa depresi yang berkepanjangan dapat berkelanjutan menyebabkan kematian. Sehingga kesehatan mental merupakan faktor yang dominan harus diperhatikan untuk kesejahteraan masa usia lanjut (Johana, 2004).

Menghadapi usia lanjut dengan sejahtera sangat ditentukan oleh peran serta dan dukungan penuh dari keluarga. Hal ini dikarenakan keluarga adalah pihak yang mengenal dan memahami berbagai aspek dalam diri anggota keluarga dengan jauh lebih baik dari pada orang lain (Heward, 2006). Keluarga dalam hal ini adalah lingkungan terdekat dan utama dalam kehidupan lansia seperti pasangan, anak, menantu, cucu atau saudara yang tinggal satu rumah dengan lansia. ${ }^{20}$ Keberadaan keluarga dapat memperkuat setiap individu, memperbesar penghargaan terhadap diri sendiri, mempunyai potensi sebagai strategi pencegahan utama bagi seluruh keluarga dalam menghadapi tantangan kehidupan sehari-hari serta mempunyai relevansi dalam masyarakat yang berada dalam lingkungan yang penuh tekanan (Ambari, 2010).

Desa Marunggi adalah wilayah Kecamatan Pariaman Selatan dengan jumlah penduduk lebih dari 4500 jiwa penduduk. Sejumlah $4 \%$ dari penduduk itu adalah lansia yang rata-rata tinggal sendiri tanpa keluarga, dan sisanya tinggal bersama keluarga tetapi kurang mendapatkan dukungan. Peneliti menemukan 10 orang lansia di Desa Marunggi yang memiliki tanda-tanda adanya depresi, antara lain: hilangnya minat atau kesenangan dalam aktivitas-aktivitas yang biasa, rasa sedih, ketidak berdayaan, dan pesimis yang berhubungan dengan suatu penderitaan dan ingin cepat mati. 
Studi pendahuluan ditemukan lansia mengatakan sedih dan tidak berharga karena sudah tua tidak bisa apa-apa dan cepat lelah, lansia mengatakan tidak bergairah dalam menjalani hidup karena merasa dirinya lemah dan tidak bermanfaat, merasa ingin segera cepat dipanggil yang kuasa, lansia mengatakan tetap bersyukur dan menjalani hidup dengan bahagia melalui kegiatan yang bermanfaat, karena keluarga selalu memberi dukungan untuk tetap semangat dan sabar, keluarga selalu memberi motivasi bahwa masih ada keluarga yang peduli, keluarga selalu meyakinkan bahwa seorang lansia bisa saja selalu sehat, keluarga selalu mendorong untuk selalu berdo'a agar selalu sehat. Penelitian ini bertujuan untuk mengetahui hubungan dukungan keluarga dengan tingkat depresi pada lansia.

\section{METODE}

Desain penelitian ini menggunakan deskriptif korelasi dengan pendekatan secara cross sectional.Populasi dalam penelitian ini adalah semua lansia di Desa Marunggi sebanyak 114 lansia.Jumlah sampel dalam penelitian ini sebanyak 114 lansia.Teknik pengambilan sampel dalam penelitian ini menggunakan purposive sampling.Penelitian dilakukan pada bulan Maret -Juni 2017 dengan alat penelitian menggunakan kuesioner karakteristik lansia, kuesioner dukungan keluarga, dan Kuisioner Geriatric DepressionScale (GDS).Data dianalisis menggunakan uji Chi Squarse Test.

\section{HASIL DAN PEMBAHASAN}

Tabel 1Hubungan dukungan keluarga dengan tingkat depresi Lansia

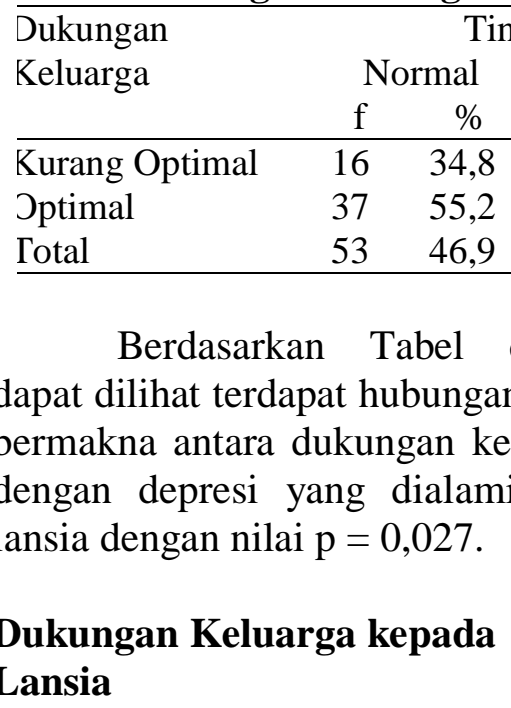

Hasil penelitian menunjukkan dukungan keluarga lansia di Wilayah Kerja Puskesmas Marunggi sebagian besar lansia mendapatkan dukungan Tingkat Depresi Lansia

Ringan Berat Total $P$

\begin{tabular}{ccccccc}
$\mathrm{f}$ & $\%$ & $\mathrm{f}$ & \multicolumn{1}{c}{$\%$} & $\mathrm{n}$ & $\%$ & Value \\
\hline 21 & 45,7 & 9 & 19,6 & 46 & 100 & 0,027 \\
26 & 38,8 & 5 & 7 & 68 & 100 &
\end{tabular}

$\begin{array}{llllll}47 & 41,6 & 14 & 11,5 & 114 & 100\end{array}$

keluarga yang optimal yaitu sebanyak 68 orang dan sebagian lansia mendapatkan dukungan keluarga yang kurang optimal yaitu sebanyak 46 orang. Sebagai sebuah keluarga yang terdapat lansia, hasil penelitian menunjukkan dukungan keluarga yang diberikan kepada lansia dapat dikatakan baik. Teori menurut Friedman (2010) berpendapat bahwa fungsi dasar keluarga antara lain adalah fungsi afektif, yaitu fungsi internal keluarga 
untuk perlindungan psikososial dan dukungan terhadap anggotanya. Hal ini menunjukkan bahwa keluarga dari lansia di Wilayah Kerja Puskesmas Marunggi telah berfungsi dengan baik, keluarga mampu memberikan perlindungan psikososial kepada lansia.Dukungan keluarga tersebut tentunya diharapkan dapat menurunkan masalah psikologis seperti, depresi.

Dukungan keluarga yang baik juga dapat dipengaruhi oleh bentuk keluarga yang ada dalam keluarga tersebut. Hal tersebut didukung juga oleh teori dari Friedman (2010), yang menjelaskan bahwa ukuran keluarga berpengaruh terhadap pola dukungan yang diberikan oleh anggota keluarga kepada anggotanya yang lain. Keluarga besar akan menerima perhatian lebih banyak dibandingkan dengan bentuk keluarga kecil. Berdasarkan hasil penelitian dan beberapa literatur dapat peneliti simpulkan bahwa dukungan keluarga yang diberikan pada lansia optimal, dan dapat dikatakan baik.

\section{Tingkat Depresi pada Lansia}

Hasil penelitian juga menunjukkan terdapat 21 orang $(45,7 \%)$ dengan tingkat depresi ringan, dan 26 orang $(38,8 \%)$ dengan tingkat depresi berat. Hal ini menunjukkan kejadian depresi pada lansia di Wilayah Kerja Puskesmas Marunggi mayoritas mengalami depresi ringan.Temuan ini memperlihatkan bahwa prevalensi kasus depresi pada lansia di Wilayah Kerja Puskesmas Marunggi cukup tinggi, bila dibandingkan dengan temuan terkait depresi pada lansia seperti yang dikemukakan Dewi dkk (2007), sebesar 6,5\%, maupun pendapat Dharmono (2008), Lyness et al (2009), yang rata-rata mengungkapkan prevalensi depresi di komunitas sekitar 10-15 \%. ${ }^{15}$

Tingginya prevalensi depresi pada lansia sangat erat dikaitkan dengan berbagai faktor yang memungkinkan terjadinya depresi, seperti sebagai dampak proses menua yang alamiah, yang menimbulkan konsekwensi berupa penurunan seluruh anatomi dan fungsi tubuh maupun konsekwensi negatif akibat menua (Maryam, 2011), sehingga lansia memiliki risiko tinggi mengalami depresi. Kondisi menua ditambah dengan faktor penyakit yang didapat, kondisi psikososial yang terganggu akibat kehilangan, akan menimbulkan konsekwensi fungsional negatif bagi lansia. Bentuk konsekwensi fungsional negatif berupa terjadinya gangguan self esteem yang dapat mengakibatkan terjadinya depresi (Mauk, 2010).

\section{Hubungan antara Dukungan Keluarga dengan Tingkat Depresi pada Lansia di Wilayah Kerja Puskesmas Marunggi}

Hasil penelitian menunjukan hubungan antara dukungan keluarga dengan tingkat depresi pada lansia berdasarkan kategori masing-masing yaitu lansia dengan dukungan keluarga yang kurang optimal terdapat 20 orang $(45,7 \%)$ yang mengalami tingkat depresi ringan, 17 orang $(34,8 \%)$ yang mengalami tingkat depresi dalam batas normal dan 9 orang $(19,6 \%)$ yang mengalami tingkat depresi berat. Lansia dengan dukungan keluarga optimal terdapat 36 orang $(55,2 \%)$ yang mengalami tingkat depresi 
dalam batas normal, 25 orang $(38,8 \%)$ yang mengalami tingkat depresi ringan dan hanya 4 orang (6\%) yang mengalami tingkat depresi berat.

Hasil penelitian ini dapat dikatakan bahwa lansia yang mendapatkan dukungan keluarga yang kurang optimal cenderung mengalami depresi yang lebih tinggi dibandingkan dengan lansia yang mendapatkan dukungan keluarga yang optimal. Hasil uji statistikdiperoleh pula nilai $\rho$ value $=$ 0,027 ( $\rho$ value $<0,05$ ), artinya ada hubungan antara dukungan keluarga dengan tingkat depresi pada lansia di Wilayah Kerja Puskesmas Marunggi. Hasil ini sesuai dengan pendapat Taylor (2009) yang menyebutkan bahwa dukungan keluarga merupakan sumber eksternal yang dapat memberikan bantuan bagi lansia.Menurut pendapat Saryono (2010), dukungan keluarga dapat membantu untuk mencegah stres dan sesuatu yang berbahaya atau mengancam.

Hasil penelitian sejalan dengan penelitian yang dilakukan oleh Lyness (2009) yang mengatakan bahwa ada hubungan antara dukungan keluarga dengan terjadinya depresi, dimana peluang lansia yang dukungannya kurang untuk terjadi depresi sebesar 5,76 kali. $^{15}$ Hasil penelitian juga didukung oleh Santrock (2013) bahwa adanya dukungan keluarga yang baik dapat meningkatkan kesehatan fisik dan kesehatan mental bagi para lanjut usia. Sarafino (2010) mengemukakan bahwa efektivitas dukungan tergantung dari penilaian individu, dimana dukungan akan menjadi lebih efektif apabila dukungan tersebut dinilai adekuat oleh individu penerima, dan bagaimana individu menerima dukungan keluarga, lebih merupakan suatu pengalaman pribadi yang melibatkan penghayatan masing-masing individu terhadap hubungannya dengan keluarga.

\section{SIMPULAN}

Karakteristik lansia di Wilayah Kerja Puskesmas Marunggi sebagian besar usia 60-74 tahun, berjenis kelamin laki-laki,masih mempunyai pasangan, tidak sekolah, tidak bekerja, tidak ada pendapatan dan tipe keluarga besar.Dukungan keluarga kepada lansia di Wilayah Kerja Puskesmas marunggi sebagian besar optimal.Tingkat Depresi pada Lansia di Wilayah Kerja Puskesmas marunggi sebagian besar dalam batas normal. Ada hubungan antara dukungan keluarga dengan tingkat depresi pada lansia di Wilayah Kerja Puskesmas Marunggi dengan nilai $\mathrm{p}$ $=0,027$ (pvalue $<0,05)$.

\section{SARAN}

Keluarga yang mempunyai lansia diharapkan selalu menyikapi kenyataan secara positif bahwa merawat lansia akan selalu diberikan anugerah yang terbaik dari Tuhan dan selalu mengoptimalkan kesejahteraan lansia dan berbagai potensi yang masih dimiliki oleh lansia tersebut agar tidak terjadi depresi pada lansia.Hal tersebut dapat dilakukan dengan memberikan dukungan emosional,informasional, penghargaan dan instrumental yang baik kepada lansia. 


\section{DAFTAR PUSTAKA}

1. Maryam, dkk. Mengenal Usia Lanjut dan Perawatannya. Jakarta: Salemba Medika.2011

2. Hawari, D. Manajemen Stres, Cemas Dan Depresi. Jakarta: FKUI. 2011

3. Giordana \& Roelandt. Mental Health of Elderly People: The Prevalence and Representations of Psychiatric disorders. Journal Encephale. 2010;36(3 Suppl):59-64. doi: 10.1016/S00137006(10)70018-X. 2010

4. Kemenkes, RI. Gambaran Kesehatan Lanjut Usia di Indonesia. Jakarta: Buletin Jendela, Data dan Informasi Kesehatan :Kemenkes, RI. 2013

5. Dinas Kesehatan Provinsi Sumatera Barat Populasi Penduduk Berdasar Usia. 2014

6. Efendi F \& Makhfudi Keperawatan Kesehatan Komunitas : Teori dan Praktek Dalam Keperawatan, Jakarta: Salemba. 2009.

7. Potter, A.P., Perry, G.A. FundamentaL of Nursing : Concept, Process, and Practice. Dialih bahasakan oleh Y. Asih, M. Sumarwati, D. Evriyani, L. Mahmudah, E. Panggabean, Kusrini, S. Kurnianingsih dan E. Novieastari.2005Jakarta: EGC.

8. Yosep, I. Keperawatan Jiwa. Bandung: Refika Aditama. 2010
9. Hidayat, A.Aziz Alimul, (2007). Pengantar Dasar Keperawatan Edisi 2. Jakarta : Salemba Medika.2009

10. Arianti.(2012). Hubungan antara Dukungan Sosial dan Kualitas Hidup pada Lansia Penderita Hipertensi.Skripsi. Program Sarjana Fakultas Psikologi Universitas Airlangga.

11. Dharmono, S.s (2008). Waspadai deperesi pada lansia.

12. Darussalam.(2011). Analisis Faktor-faktor yang Berhubungan dengan Depresi dan Hopelessness pada Pasien Stroke di Blitar.Skripsi FIK UI Depok.

13. Friedman, M. (2010).Keperawatan Keluarga.Jakarta: EGC.

14. Ibrahim, A.S. (2011). Gangguan Alam Perasaan: Depresi. Jakarta: Dua As-As Dua.

15. Lyness, J.M., Yu, Q., Tang W., Conwell, Y. (2009). Risk for Depression Onsetin Primary Care Elderly Patients: Potential Targets for PreventiveIntervention. Am J Psychiatry.Vol 166 No 12.2009.

16. Mauk, K.L. (2010). Gerontological Nursing: Compentecies for Care. (2nd ed). Canada: Jones and Bartlett Publishers

17. Stewart. (2014). Buku Ajar Keperawatan Gerontik. Jakarta: EGC

18. Sumirta.(2011). Psikologi untuk Keperawatan Lansia. Jakarta: EGC. 
19. Walen, H.R, Lachman, M.E. (2014). Social Support and Strain from Partner, Family, and Friends: Cost and Benefits for Men and Women in Adulthood. Journalof Social and Personal Relationships (2014),

20. Widiaswara.(2014).Perbedaa $n$ Stress Psikososial pada Janda Lansia yang Tinggal Sendiri dengan yang Tinggal Bersama Keluarga di Desa Wonosari Kecamatan Pegandon Kabupaten Kendal.Skripsi PSIK STIKES Kendal, tidak dipublikasikan.

21. Yacob. (2014).Gambaran Kognitif Pada Lansia di RSUP H. Adam MalikMedan Dan Puskesmas Petisah Medan.Diakses melalui http: http://repository.usu.ac.id . 